Joachim Boldt

Michael Ducke

Bernhard Kumle

Michael Papsdorf

Ernst-Ludwig Zurmeyer

\section{Retraction Note: Influence of different volume replacement strategies on inflammation and endothelial activation in the elderly undergoing major abdominal surgery}

Published online: 21 May 2011

(C) Copyright jointly held by Springer and ESICM 2011

The online version of the original article can be found under doi:10.1007/s00134-003-2110-7.

J. Boldt $(\bowtie) \cdot$ M. Ducke · B. Kumle $\cdot$ M. Papsdorf

Department of Anesthesiology and Intensive Care Medicine, Klinikum der Stadt Ludwigshafen,

Bremserstr. 79, 67063 Ludwigshafen, Germany

e-mail: boldtj@gmx.net

Fax: +49-621-5033024

\section{E.-L. Zurmeyer}

Department of Surgery, Klinikum der Stadt Ludwigshafen, Ludwigshafen, Germany
Retraction Note: Intensive Care Med (2004)

\section{0:416-422}

DOI 10.1007/s00134-003-2110-7

This article has been retracted as the IRB approval for the research was misrepresented. The investigating committee at Klinikum Ludwigshafen found the lack of IRB approval and this is unethical. It does not mean that the research results per se are fraudulent. The investigating committee is systematically assessing the veracity of the findings presented in Dr. Boldt's articles against patient and laboratory records. We will communicate to our readers any finding of data fabrication or misrepresentation identified by the investigating committee. 